\title{
Towards a BIM Approach for a High Performance Renovation of Apartment Buildings
}

\author{
M. Aldanondo ${ }^{1, *}$, A. Barco-Santa ${ }^{1}$, E.Vareilles ${ }^{1}$, M. Falcon ${ }^{2}$, P. Gaborit ${ }^{1}$, \\ and L. Zhang ${ }^{3}$ \\ ${ }^{1}$ Toulouse University - Mines Albi, Albi, France \\ ${ }^{2}$ TBC Générateur d'Innovation, Colomiers, France \\ ${ }^{3}$ IESEG Business School Paris, France \\ michel .aldanondo@mines-albi.fr
}

\begin{abstract}
Building renovation is a key issue for energy saving in the future. The goal of this article is to show how this traditional activity can be industrialized thanks to a BIM supported process. The critical needs are explained and the proposed BIM presented.
\end{abstract}

Keywords: BIM, Energy renovation, Industrialization, Process, Design.

\section{Introduction}

The goal of this communication is to present the first elements that allow to set up a Building Information Model (BIM) and associated process for the renovation of apartment buildings that target high energy performance. This modeling problem appears in a large French multi-partner project called CRIBA that aims to industrialize building renovation in order to reduce energy consumption. In a second section the critical needs of renovation and relevant BIM will be explained and justified. Then the main ideas of the renovation solution proposed by the CRIBA project will be presented in a third section. The fourth section deals with the modeling propositions for the BIM.

\section{BIM for Renovation: A Set of Various Cascading Needs}

We present and characterize the renovation needs in a first step. Then the reasons that push towards the industrialization of the renovation process are explained. Finally the relevant BIM need is introduced.

\subsection{Need for High Energy Performance Renovation}

The global contribution from buildings (residential and commercial) towards energy consumption has steadily increased. Buildings account for around $20 \%$ and $40 \%$ of the total final energy consumption in developed countries: $37 \%$ in the EU [1], 36\% in the USA [2] and $31 \%$ in Japan [3]. Nowadays, it has exceeded industry and

\footnotetext{
* Corresponding author.
} 
transportation sectors. Growth in population, enhancement of building services and comfort levels, together with the rise in time spent inside buildings assure the upward trend in energy demand will continue in the foreseeable future. Reducing energy consumption of the building sector is therefore one of our century challenges.

In several countries, research works are carried out on the efficient measures to take in order to reduce energy consumption of the building stock. Most states set regulations to improve the energy performance of new buildings. Huge progresses have been realized in the materials and in the building processes. Thus it is now possible to build very low consumption buildings at reasonable costs. However, the annual rate of construction of new dwellings is only $1.1 \%$ in Europe [4]. At current rates, it would take nearly a hundred years to upgrade the energy efficiency of the existing building stock. It is therefore indispensable to renovate the existing buildings to reduce their energy consumption.

\subsection{Need for the Industrialization of the Renovation Process}

Nowadays, energy-efficiency renovation activities are currently still at the craftsman stage. Most of the time, the measurement are taken on site, then the materials are cut on demand directly on the building site in order to fit. The frames (windows, doors, solar modules...) are adjusted on site with waste of materials. Finally, cladding is attached according to the architect expectations. Most of these activities are achieved on the building site with a very low degree of anticipation. As a result, the effectiveness of the working site is low, the energy efficiency of the renovation is questionable and renovation costs tend to increase.

If you consider for example that there are about 20 million apartments in France, half of which were built before 1975 (when the first energy regulation was issued), that means that there are around 400000 energy-inefficient buildings to renovate. Given these figures, it is clear that the building renovation process cannot remain at the craftsman stage and needs to be considered as an industrial activity. The main idea behind this industrialization is to distinguish: the existing building analysis, the renovation design, and the components production, from the renovation assembly on the building site. This allows to design, to prepare and to produce all the renovation components in factories with some anticipation allowing waste reduction and some optimization concerns. Then, all components are moved towards the building site for renovation assembly with a minimum of adjustments or fitting.

\subsection{Need for a BIM to Support the Renovation Process}

The industrialization need and the volume of renovations under consideration require three key elements:

- A technical concept allowing insulation by the assembly of off-the-shelf modular components with a minimum of specific components,

- A chain of stakeholders including renovation owner, renovation designers, architects, modular component suppliers, and on the building site installation teams,

- A digital engineering chain that can provide aiding tool for supporting each task of the renovation process [5]. 
We mean by digital engineering the entire chain of digital tools, ranging from initial scans and building analyses (required before renovation for measurement and specification of the existing building) up to the detailed plans of the renovated building (once renovation has been carried out) which will be supplied to the owner or building managers for maintenance and future adaptations.

Given this goal, it is obvious that the renovation process is collaborative. Thus all the stakeholders will need to share data, information and knowledge at the various steps of the renovation process. Furthermore, as explained in [6] most of the times they will want to use their own specific software tool (scanning package, computer aided design, finite elements, heating simulation, cost estimators, computer aided manufacturing, transport optimization, project manager...). In order to guaranty a minimum of consistency, it is necessary to share a same renovation model between all the stakeholders and therefore to support the whole process with a Building Information Modeling software (BIM software) [6]. Although if numerous studies have examined these tools for new builds, very few have looked at their use in renovation, however [5] or [7] can be consulted. Thus the goal of this article is to propose the first modeling elements relevant to a BIM dedicated to the renovation of apartment buildings that target high energy performance. This is achieved with respect to the key propositions relevant to BIM solutions like Open BIM, 4D or 5D-BIM as explained in [8]. Naturally these modeling elements are strongly dependent of the technical concepts used for renovation. Thus, the third section will present the renovation concept of the CRIBA project and the fourth one the modeling propositions.

The technical concept is quickly described, and then the compromise associated to the each specific solution design is discussed. Finally the renovation process is described introducing the BIM need.

\section{The Proposed Technical Concept and Relevant Process}

The technical concept is quickly described and then a compromise associated to the each specific solution design is discussed. Finally the renovation process is described introducing the BIM need.

\subsection{Proposed Technical Concept}

This industrialization is based on an external new thermal envelope which wraps the whole buildings. The envelope is composed of prefabricated rectangular multi-functional panels and fastener devices that are used to fix the panels on the facade. In this article we do not consider the technical concept associated to the roof and relevant

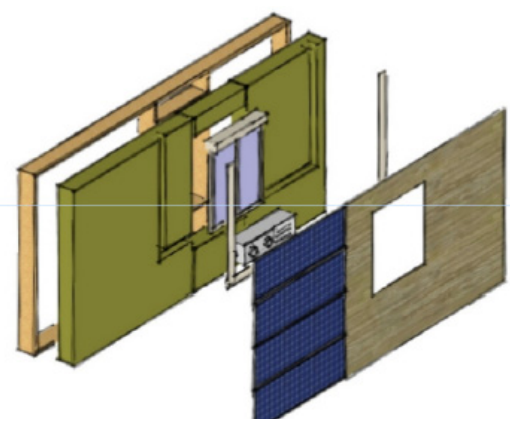

Fig. 1. Technical concept modeling elements. 
A multi-functional panel includes a wood structure, insulation material, and cladding. Some of them, as shown in Fig. 1, may include windows, doors, solar modules and even balconies (all these elements are call from now frames). The length of these panels can vary between 1 and up to 13 meters while the width is between 1 and 3 meters. These sizes limits result from the transportation and manufacturing constraints. Two types of fastener devices can be used. When the facade is of good quality, meaning that it can be loaded, each panel is attached on two (and up to four) single fasteners that are themselves directly fixed on the wall as on the upper part of figure 2. This kind of single fastener varies according to their load bearing capacity and the distance between the facade and the panels. When the facade is not strong enough, each panel is attached on a vertical metal profiles that runs all along the facade thanks to a simple fastener as on the lower part of Fig. 2. The metallic profile is attached to the wall with previous single fasteners. In some hard situations, metallic profiles may require concrete foundations. To give an order of magnitude a panel weight can vary between $200 \mathrm{kgs}$ and $2000 \mathrm{kgs}$ mainly according to size, thickness and cladding.

The main interests of this concept are: (i) it can be adapted to any facade quality, (ii) renovation can be processed with people remaining living in the building, (iii) insulation quality and thickness selections allow using this concept with various climate conditions.

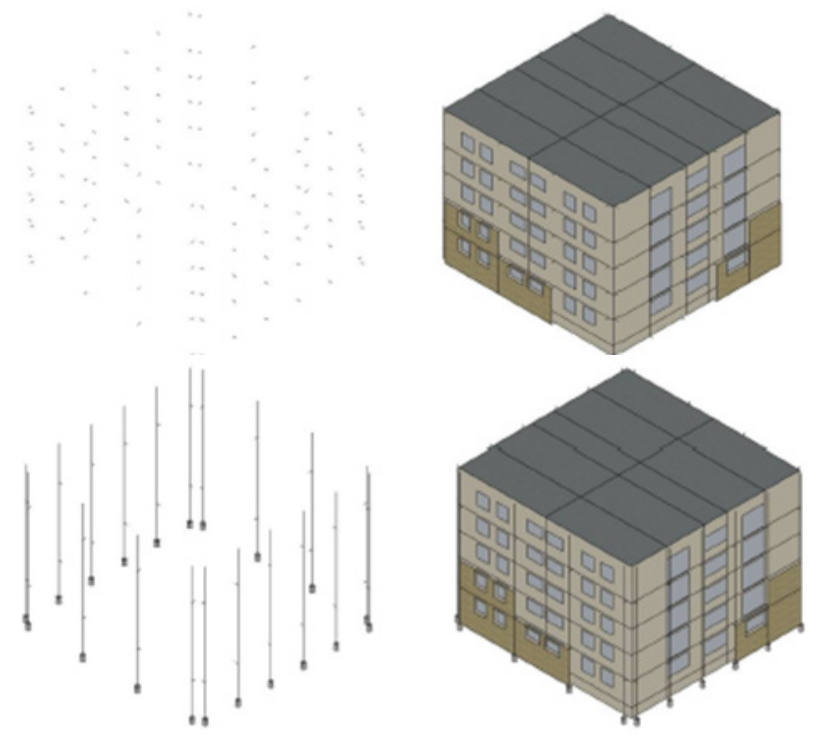

Fig. 2. Fasteners for good and poor quality facade

\subsection{Designing Specific Renovation}

Each renovation problem is specific and each renovation design is a kind of compromise. In order to minimize the average heat transfer coefficient of the façade, quantified in $\mathrm{W} /\left(\mathrm{m}^{2} \bullet \mathrm{K}\right)$, it is necessary to design panels as large as 
possible. Because energy waste is mainly concentrated around joins between panels. But when panels become large, their weight become high also and the facade is not always able to support them. Thus designing a specific renovation is often a compromise between panel sizes and fastener devices or how to maximize energy efficiency while respecting the facade acceptable load. Given these elements, the renovation process can be now described and discussed.

\subsection{Proposed Renovation Process and Identification of BIM Stakeholders}

The renovation process can be decomposed in the five sub-processes (Sp-i) starting with first dimension analysis up to renovation reception by the building owner.

\section{Sp-1: Building geometry generation.}

On the existing building the first sub process consists of getting the building geometry. Most of the time laser scanning techniques are used and produce a raw cloud of points representing the building. This cloud is processed thanks to more or less autonomous techniques and provides a first building model with a reference plane for each facade and a set of various plane shapes. This step is critical for model accuracy and renovation quality because all downstream activities rely on this first building model. Then a human user or geometry designer enriches this model. He annotates the shapes according to three types:

- Frames gathering: windows, doors, balconies that will be included in the panel,

- Object that will cross the panel: electrical boxes, antenna... that will require a hole in the panel,

- Object that will be taken off the facade before renovation assembly and attached again after as: rain gutters, street lights... They will be included in the preparation and in the finish operations of the $5^{\text {th }}$ sub-process.

Sp-2: Building analysis and renovation requirement characterization.

This sub process collects and adds four sets of information's to the previous geometry thanks to various stakeholders:

- First the robustness of the facade is analyzed by a structure expert. The reference plane of the facade is split in the three kinds of rectangles: load-bearing wall, slab nosing, and remaining areas as shown in Fig. 3. Each rectangle is analyzed in order to provide an acceptable load that will be used for fastener positioning. Each rectangle is annotated with an acceptable load and a platitude characteristic.

- Secondly the actual heat transfer performance level for each of the previous rectangle is measured with some kind of infra-red devices. This will be used for the definition of

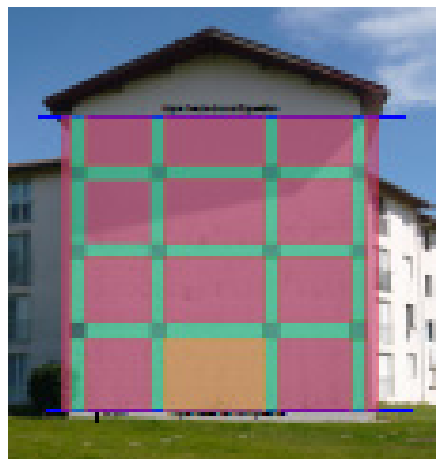

Fig. 3. Structure analysis the heat transfer coefficient of the panel and relevant insulation characteristics. 
- Thirdly, requirement or goal in terms of heat transfer coefficient is provided for each facade building. This will of course affect the selection of insulation thickness and type but also the frame energy performances.

- Lastly, requirements in terms of panel cladding must be collected. They can affect panel weight but also panel dimensions.

Sp-3: Renovation specific design.

Given previous information, it is now possible to define or more accurately configure the renovation. As explained in [9] renovation specific design can be considered and solved as a configuration problem. This sub-process generates two results:

- A bill of material of the renovation gathering the parameterized components fasteners and panels with dimensions, positions and all specific properties,

- An assembly process describing all the operations necessary to the assembly sequence that should be followed on the building site.

Sp-4: Production or manufacturing of the components of the specific renovation. Following the previous step, the component suppliers (panels and fasteners) finalized the detailed design (with detailed BOM for the panel) and manufacture the parameterized component. They also prepare the packaging for transportation.

\section{Sp-5: Renovation assembly on building site.}

This sub-process is the most critical. If previous sub-processes have been undertaken correctly, it should ran smoothly, if not it will be necessary adjust and modify supplied components. Six kinds of task have to be planned:

- Facade preparation, removing object that must be taken off and facade cleaning,

- Transportation of fastener devices,

- Fixing all fasteners (with metallic profile if necessary) on the facade,

- Transportation of panel according to assembly sequence,

- Panel assembly on already fixed fasteners,

- Facade finish, some gasket can be added, fixing object that were removed.

Of course the sub-processes Sp-4 and Sp-5 must overlap in order to avoid huge panel inventory. A hard and not easy scheduling problem exists here. Finally after the renovation assembly, the reception by the building owner can occur and the maintenance of the building with its new renovation can start. Of course panel can be damaged and of course changed if necessary. It is clear that all this process must be supported by a BIM software and relevant model. The final section proposes adequate modeling elements.

\section{$4 \quad$ BIM Propositions}

BIM propositions are attached to each façade. Thus before detailing the façade, we first present how upper level objects of the hierarchy are defined. 


\subsection{Main Objects from Building site to the Facade}

Four levels of abstraction are considered providing four objects that take part in the renovation. Some properties are attached to each of them.

- Working site: Is the bigger spatial division in the renovation. It is commonly referred by a name and brings attached crucial aspects for the renovation process, e.g., accessibility constraints and weather. Such entity is divided into blocks. A working site is characterized by: (i) a wind level, (ii) a level of accessibility for heavy truck..

- Block: Is a set of buildings which are usually attached by a common wall. A block has also accessibility constraints which as the same time has an impact on the panel sizes possibilities.

- Building: This is the actual place where apartment are arranged. It is the host of several facades and has dimensions (height and width). It is also characterized with space availability in order to park a truck or for some inventory purposes.

- Facade: A facade is a composition of apartments along with its doors, windows and so on. A reference plane (introduced in section 3.) will be attached to each façade..

These four elements are characterized by various referential and coordinate. We consider in the following the reference plane of the facade.

\subsection{BIM Information and Knowledge}

Five sets of information and knowledge (IK-i) are attached to each façade. They are associated with the five previous sub-processes.

IK-1: Initial façade geometry that can contain:

- IK-1.1 is the cloud of points that can be obtained by laser scanning. If the geometry is provided with a CAD file, this first element is not necessary.

- IK-1.2 is the reference plane of the façade. This plane is either extracted from the cloud or from the CAD file. It is a vertical plane tangent to the façade at a minimum distance of $2 \mathrm{~cm}$ of the façade. This plane corresponds with the back of the panels or the back of the vertical metallic profiles. A referential is attached to each reference plane. The plane has the height and the width of the façade. For simplicity we assume rectangle facades.

- IK-1.3 is the set of frames. Each frame is characterized by a type with sub-types (windows, door, balcony...) dimensions $(\mathrm{w}, \mathrm{h})$ and positions $(\mathrm{x}, \mathrm{y})$ in the reference plane.

- IK-1.4 is the set of objects that will cross the panels. Each of them is characterized by a type (electrical boxes, antenna..), a 2D shape defined with a position (x,y) on the reference plane.

- IK-1.5 is the set of objects that will be taken off and attached to the panels. Each of them is characterized by a type (rain gutters, street lights...), a 2D shape defined with a position $(\mathrm{x}, \mathrm{y})$ on the reference plane and a weight because they will be supported by the panel. 
IK-2: building analysis and renovation requirements that can contain

- IK-2.1: is a set of rectangles that corresponds with the intersection of load-bearing wall and slab.

- IK-2.2: is a set of rectangles that corresponds with the slab nosing minus IK-2.1.

- IK-2.3: is a set of rectangles that corresponds with the load-bearing wall minus IK-2.1.

- IK-2.4: is a set of rectangles that corresponds with the remaining areas of the façade.

Each rectangle of these four elements is characterized by:

- dimensions (h,l) and positions (x,y),

- an acceptable load per meter/square estimated by structure engineer,

- a (min,max) distance between reference plane and façade if a cloud is available extracted from the BIM,

- a heat transfer level measured or estimated by a thermic engineer.

- IK-2.5: is an expected global heat transfer level for the whole façade, it is a requirement established by the owner and the thermic engineer. When you have this parameter for each façade, you can compute the global energy performance of the building.

- IK-2.6: is a set of rectangles (or sometimes shapes) provided by the architect that corresponds to the cladding of the façade. Cladding is characterized by a weight and sometime dimensions.

IK-3: Renovation description that represents all the component of the BOM of the renovation:

- IK-3.1: is a set of single fasteners (panel/façade, without metallic vertical profiles),

- IK-3.2: is a set of single fasteners (profile/facade, with metallic vertical profiles),

- IK-3.3: is a set of simple fasteners (panel/profile, with metallic vertical profiles), All these fasteners are characterized by a type, positions (x,y), an acceptable load. Single fasteners have also a maximum acceptable overhang compatible with the distance between reference plane and facade.

- IK-3.4: is a set of vertical profiles, characterized by dimensions (x,y) and positions $(\mathrm{x}, \mathrm{y})$.

- IK-3.5: is a set of multi-functional panels, characterized by dimensions (x,y), panel thickness, positions $(\mathrm{x}, \mathrm{y})$, insulation type, and insulation thickness. If a frame is present: frame type (windows, door,...), dimensions $(\mathrm{x}, \mathrm{y})$ and positions $(\mathrm{x}, \mathrm{y})$. A panel is also characterized by its weight and its heat transfer coefficient.

Renovation description shows also the assembly process. Globally each physical component belonging to IK3-i ( $\mathrm{i}=1$ to5) has an assembly order. This information can be processed with BIM-4D solutions in order to detect conflicts as explained in [10] It is admitted that for a façade, all fasteners must fixed before starting panel mounting.

IK-4: Component detailed descriptions are mainly used for panel and fastener detailed description that depends on the component suppliers. Detailed parametric CAD de- 
sign of each component must be provided by the supplier. They will be scaled at the good dimensions and located at the good positions defined in IK3 and included in the BIM.

IK-5: Renovation assembly description is mainly used to describe where each physical component has been effectively mounted and if possible when. In a perfect world with no hazards, this information set should match IK-3 and IK-4.

The renovation process, the main stakeholders, the information and knowledge feeding the BIM are synthetized in the figure 4. The storage of information and knowledge is following the IFC standard [11] in order to offer, even if not full proof, some sharing and interoperability possibilities.

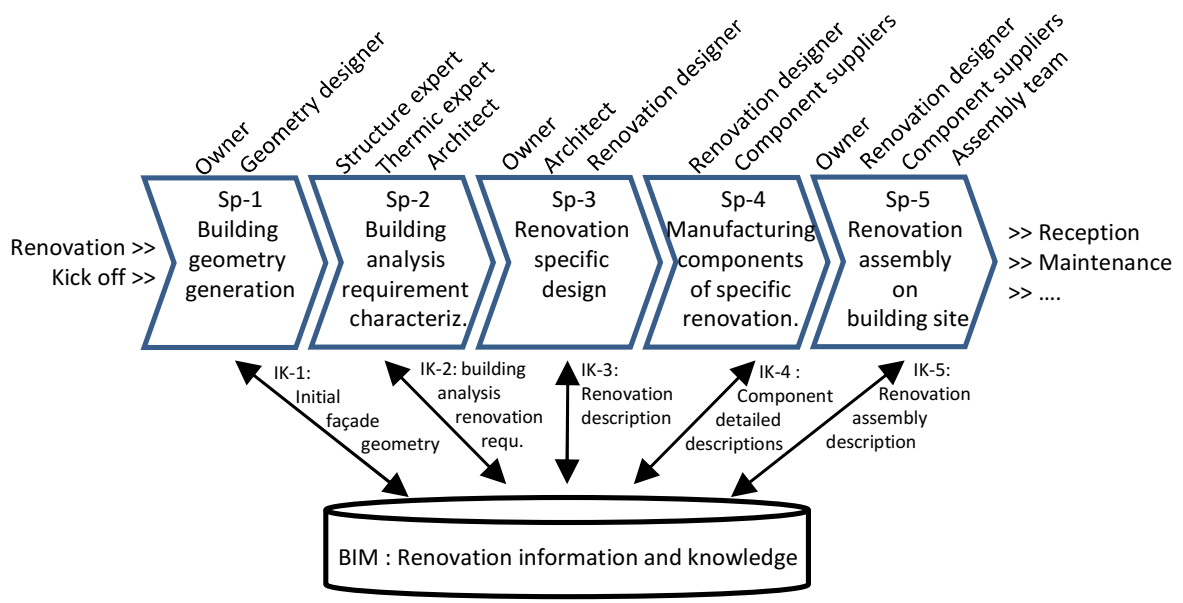

Fig. 4. Renovation process and relevant BIM

\section{Conclusions}

The goal of this article was to present the first elements allowing proposing a Building Information Model (BIM) and associated definition process for the renovation of apartment buildings that target high energy performance. The needs for energy renovation, industrialization of the renovation, digital engineering chain supported by BIM software have been explained. Then the technical concept defined during the CRIBA project for the renovation solution was presented. It is based on a set of off-the-shelf modular components (parametric or standard). Then the renovation process and associated information and knowledge have been proposed. At the present time, a numerical mockup of this engineering chain is in development and the renovation of a real working site gathering 4 blocks of 110 apartments will start this summer in the south of France. 


\section{References}

1. Perez-Lombard, L., Ortiz, J., Pout, C.: A review on buildings energy consumption information. Energy and Buildings 40(3), 394-398 (2008)

2. U.S. Green Building Council. New Construction Reference Guide (2013)

3. The Energy Conservation Center. Energy Conservation Handbook. Japan (2012)

4. Poel, B., van Cruchten, G., Balaras, C.A.: Energy performance assessment of existing dwellings. Energy and Buildings 39(4), 393-403 (2007)

5. Juan, Y.K., Gao, P., Wang, J.: A hybrid decision support system for sustainable office building renovation and energy performance improvement. Energy and Buildings 42(3), 290-297 (2010)

6. Eastman, C., Teicholz, P., Sacks, R., Liston, K.: BIM Handbook, 2nd edn. Wiley (2011)

7. Martinaitis, V., Kazakevičius, E., Vitkauskas, A.: A two-factor method for appraising building renovation and energy efficiency improvement projects. Energy Policy 35(1), 192-201 (2007)

8. Popova, V., Juoceviciusa, V., Migilinskasa, D., Ustinovichiusa, L., Mikalauskasb, S.: The use of a virtual building design and construction model for developing an effective project concept in 5D environment. Automation in Construction 19, 357-367 (2010)

9. Vareilles, E., Langhoff, C., Falcon, M., Aldanondo, M.: Interactive configuration of high performance renovation of apartment buildings by the use of CSP. In: Proceedings of the 15th Int. Configuration Workshop, Vienna, Austria (2013)

10. Zhang, J.P., Hu, Z.Z.: BIM- and 4D-based integrated solution of analysis and management for conflicts and structural safety problems during construction: 1. Principles and Methodologies, Automation in Construction 20, 155-166 (2011)

11. Howard, R., Bjork, B.C.: Building information models-experts' views on BIM/IFC developments. In: Proceedings of the 24th CIB-W78 Conference, Maribo, Slovenia (2007) 